\title{
Waiting times in aged care: what matters?
}

Serena $\mathrm{Yu}^{\mathrm{a}}$ and Julie Byles ${ }^{\mathrm{b}}$

a. Centre for Health Economics Research and Evaluation, University of Technology Sydney

b. Research Centre for Generational, Health and Ageing, University of Newcastle

\section{Corresponding author:}

Name: Dr. Serena Yu

CHERE, University of Technology Sydney

Level 2, Building 5, Block D

1-59 Quay St, Haymarket NSW 2000

Phone: +61 295149884

Email: serena.yu@chere.uts.edu.au

MeSH keywords: residential facilities, health services for the aged, public policy, socioeconomic factors

\section{Acknowledgements}

The research on which this paper is based was conducted as part of the Australian Longitudinal Study on Women's Health by the University of Queensland and the University of Newcastle. The authors acknowledge the Departments of Health and Veterans' Affairs for providing Aged Care data, and the Australian Institute of Health and Welfare (AIHW) as the integrating authority. We are grateful to the Australian Government Department of Health for funding and to the women who provided the survey data. This research was supported by the UTS Business School Research Grant. The authors declare that they have no conflicts of interest to report. 


\title{
Waiting times in aged care: what matters?
}

\author{
Abstract \\ Objective: To assess consumer-level socioeconomic factors associated with waiting times for \\ access to aged care services, specifically community-based care and permanent residential \\ care. \\ Methods: Administrative data on assessment outcomes and admissions to services were \\ linked with survey data at the person-level, and were used to implement a competing risks \\ regression model. We estimated the association between health needs, and socioeconomic \\ variables and subsequent waiting periods for individuals with approval for access. \\ $\underline{\text { Results: }}$ The main consumer-level factors driving waiting time were the individual's assessed \\ needs, including health status, whether they lived alone, and age. We found no evidence that \\ socioeconomic status was associated with waiting times for community-based care; however \\ admission to residential care reflected socioeconomic factors including education levels and \\ geographical isolation.
}

Conclusions: This paper provides baseline evidence for factors affecting wait times in aged care, essential for evaluating subsequent policy reforms aimed at reducing wait times and increasing equity of access and consumer choice.

MeSH keywords: residential facilities, health services for the aged, public policy, socioeconomic factors

\section{Introduction}

Significant recent media and policy attention has recently been paid to waiting periods for aged care services, with media reports citing waits of up to two years for home-based care services [1,2]. In response to significant variation in waiting periods across the country [3], in February 2017 the Australian Government introduced the National Prioritisation System, a national queuing process which prioritises access according to need and allocates Home Care Packages. Home Care Packages (HCP) are provided on 4 levels, referring to basic (level 1), low, intermediate and high (level 4) care needs. At that time the Government reported that beyond 53,750 consumers in the national queue, a further 35,154 were receiving care at a lower level than approved while waiting for their approved care [4]. Over 63 percent of 
consumers were waiting for level 4 care. More recent national figures released in March 2018 show that the queue had increased to 108,456 people waiting for home care packages, a $3.7 \%$ increase from the previous quarter [5].

Despite rising concern about access to aged care and prolonged waiting times, there is little empirical evidence on the determinants of waiting times. According to the My Aged Care website, the expected wait time is around 3-6 months for a Level 1 home care package, and more than 12 months for a level 4 package [6]. The Productivity Commission reported that in 2017/18, 42.3 per cent of older people commenced home care within 3 months of their ACAT approval [7], down from 56.3 percent the previous year [8]. Waits for residential aged care have a median wait time of 121 days (up from 84 days in 2015/16), with $44.7 \%$ of people moving into residential aged care within three months of approval by a local assessment team [7].

These wait times can be affected by many factors, including availability of services, the older person's preferences and circumstances, and their level of need, and variation in wait times is likely across the population. However, there are few studies of variation in waiting times by individuals' needs and characteristics. In addition, there is virtually no public reporting of performance data in aged care, compared to, for example, published wait times in the hospital sector. In this paper, we used survey-linked administrative data to examine whether there is a socioeconomic gradient associated with access to services, and provided baseline measures for future performance reporting. Importantly, our analysis examined service access and wait times from the point of view of the individual and their need for care, rather than the service providing care. The richness of the assessment data, which are recorded by a multidisciplinary team of assessors, allows us to control for the needs of those approved for services.

\section{Methods}

$\underline{\text { Data }}$

The analysis drew on multiple administrative datasets linked to survey data from the Australian Longitudinal Study on Women's Health (ALSWH). The ALSWH is a national, longitudinal study of women's health, commencing in 1996 with over 57,000 women in four cohorts. The ALSWH was chosen as it was the only survey with rich data on socioeconomic characteristics linked to individual unit record administrative data on aged care. In this study, we focused on the cohort born between 1921 and 1926, including 12,432 women aged 70 to 
75 years of age when they participated in the first wave of the survey in 1996 [9]. Attrition in the cohort was mostly due to death; however Brilleman et al. [10] noted that non-death attrition may be a greater source of bias, particularly in light of non-respondents with poor self-rated health. In this analysis we overcame some of this bias by also including aged care administrative data on assessed need (see below).

We focused on survey waves 3 (2002) - 6 (2011), representing women as they aged from 7984 years to $85-90$, and corresponding most closely to the administrative aged care data available for the years 2005-2014. However, some demographic variables (e.g. education) were only asked at Survey 1 . The ALSWH survey variables provided information on financial and social resources which may influence access to aged care.

The Australian Longitudinal Study on Women's Health is funded by the Australian Government Department of Health. Ethics approval was obtained from the Universities of Newcastle and Queensland (Ethics approvals H0760795 and 2004000224).

Administrative aged care data held in the National Aged Care Data Clearinghouse (NACDC) were linked to ALSWH survey data by the Australian Institute of Health and Welfare (AIHW) [11]. The NACDC uses a statistical linkage key (SLK) to identify clients across multiple datasets; although 11,457 individuals were linked using the SLK, it is unclear what the linkage rate was between the survey and administrative data, because the linkage included ALSWH participants in the 'mid cohort' (aged 45- 50 at the start of the survey). In this study we used data on the Aged Care Assessment program (ACAP) and admissions to aged care services.

ACAP data are collected by the Commonwealth government from all national Aged Care Assessment Teams (ACATs). The data provide results from a comprehensive assessment of the needs of individuals, and the approvals received for different care packages.

Data on admissions to Commonwealth-funded aged care service programs is also collected nationally. Data on admissions include the service program, the duration of each stay, and the entry and discharge dates. 
We used completed assessment data available over the period from 2003 to 2014, linked to admissions data over the same period. We map the most recent survey data to each assessment outcome. For example, survey data from wave 4 (2005), were mapped to approvals which took place between an individual's wave 4 and wave 5 survey dates.

Death data were obtained from the National Death Index up to 30 June 2014.

\section{$\underline{\text { Study design }}$}

For simplicity, we rationalised all community-based programs into one category and counted an admission as the start of an episode of care. Transfers between programs (within community care) do not constitute a new episode of care. We counted admissions to, and transfers within, permanent residential aged care (PRAC) in a similar manner. We ignored episodes of respite care, as these are, by definition, short stays designed to give carers a short reprieve. We defined the waiting period as the number of days between the ACAP approval date and either the first admission date to either community care or PRAC, or date of death. For waiting periods which commenced after August 13 2003, and ended before 30 June 2014, we observed complete waiting periods. We did not observe the complete waiting period for those waiting after 30 June 2014 - these were right-censored. Our econometric model accounted for the right-censored nature of the data.

Waiting periods vary for a multitude of reasons, including the individual's preference for staying at home, service availability, and the need to take care of legal/financial matters (e.g. selling the home). It is important to note that our analysis refers more strictly to elapsed time, rather than waiting time, because we did not observe why an individual entered aged care when they did, nor did we observe if they preferred an alternative pathway.

We implemented a competing risks regression model [12], given by:

$$
h_{i k}(t)=h_{0 k}(t) \exp \left[\boldsymbol{x}_{\boldsymbol{i}}(\boldsymbol{t})^{\prime} \boldsymbol{\beta}\right]
$$

where $h_{i k}(t)$ is the subdistribution hazard for individual $i$ and event type $k, h_{0 k}(t)$ is the baseline hazard common to all individuals for event type $k$, and $\boldsymbol{x}_{\boldsymbol{i}}(\boldsymbol{t})$ is a vector of individual characteristics. The subdistribution hazard is the instantaneous rate of occurrence of the given 
type of event for individuals who have not yet experienced an event of that type. In this model, the events, or 'competing risks' are denoted by $k(\mathrm{k}=1,2,3)$, representing entry into community care, PRAC, or death. The covariates of interest $\boldsymbol{x}_{i}(\boldsymbol{t})$ were categorised as socioeconomic survey variables (including an indicator of remoteness of their location, the level of local socioeconomic disadvantage, state, whether they live alone, age, as well as proxies for available financial and social resources), and variables of need and health status. The variables that captured need and health include ACAP data on whether an individual needs assistance with daily activities and a record of health conditions. Finally, a variable denoting whether the ACAP assessment took place in hospital was used to proxy for the urgency of care services.

Our main analysis was based on individuals whose completed assessment outcome was observed during the sample period. We excluded those who did not apply for any services, and those without approval to access services. Of the 6707 respondents in Wave 3 (2002) of the survey, 2379 received approval for any service in our data period (including women with multiple assessments). This exclusion was designed to limit the sample to those assessed as in need of care, and where we had rich information on those needs.

\section{Results}

Our competing risks model assumed that all individuals are 'at-risk' of each event type; consequently, the sample comprised assessment outcomes where approval for both community care and PRAC was granted, and resulted in 1095 assessments with complete data. We also separately analysed assessments receiving approval for PRAC only $(\mathrm{n}=1068)$, and for community-based care only $(\mathrm{n}=449)$. Of our sample of individuals approved for either service, 47 died before accessing care services, and 47 were right-censored. Table 1 provides some summary statistics of our sample of individuals approved for care. In our overall sample (column 5), the mean age is 86.1 , over a third were NSW residents, $54.6 \%$ lived outside metropolitan areas, and $85.5 \%$ reported being a concession cardholder. The data also show that 61.5 percent of the sample lived alone. Around 36.0 percent lacked social support for daily activities, while around 16.3 percent lacked emotional support. While we did not have individual-level data on financial resources, we had a number of proxies, 
including level of educational attainment and income sources. In wave 1 of the survey, $12.4 \%$ reported finishing Year 12 high school, while 71.4\% attained Year 11 or below.

Table 1 also indicates some observed differences between the few women who did not access services $(n=47)$, and those who went into community care $(n=1882)$ or PRAC $(n=2948)$. While very few did not access services after approval $(n=47)$, these individuals were more likely to have social resources than those in other groups - they were less likely to live alone, and only 4.3 percent of those not accessing services reported lacking a confidante to share worries with (compared to 16.3 percent overall). They were also more likely to live in metropolitan areas, where other community services may be more accessible. On average, the elapsed time for those not using services was 548 days. In the regression analysis, we undertook a sensitivity analysis removing 23 right-censored observations with wait times exceeding 365 days. These individuals may have been in hospital, or accessing Department of Veterans' Affairs services, data we did not observe. The results were not materially different from those reported in Table 3.

On average, the elapsed period for those accessing community care was 159 days, compared to 101 days for those entering PRAC. Comparing women who accessed PRAC and community-based services, the data show that individuals who entered PRAC were more likely to live alone and be concession cardholders.

While very few women died before receiving services $(n=47)$, these individuals were more likely than their counterparts to have low education levels, be concession cardholders, and live in disadvantaged areas.

In Table 2 we report on assessed needs. These include a range of conditions, including dementia, hip fractures/falls, and amnesia/memory loss, and are available in full on request. The data show that 42.6 percent of approved individuals had mental and behavioural conditions, including dementia, while 60.1 percent experienced conditions including amnesia, falls and disorientation.

Unsurprisingly, there was variation in need according to the services accessed. Individuals who accessed PRAC are much more likely to have mental/behavioural conditions or experience frequent falls or disorientation, compared to those who accessed community- 
based care. Access to community-based care was also associated with requiring assistance with communication, health, meals, bodily movement, and self-care. These supports are typically delivered through home-based services [13]. While those who did not access services required assistance with a similar range of activities, they were far less likely to have mental or behavioural conditions.

[Table 1 about here]

[Table 2 about here]

Figure 1 presents the cumulative incidence function for entry to community-care or PRAC for individuals approved for both. This can be thought of as the probability of experiencing event type $k$ by time $t$, accounting for the fact that an individual's wait time may end for other reasons. The chart shows that a representative individual ${ }^{1}$ was more likely to enter community-care, and had about a 30 percent chance of accessing community care within 100 days (about a 20 percent chance of entering PRAC). There was around a 53 percent chance that an individual would gain access to community care, and about a 39 percent chance they would enter PRAC, within 500 days. Examination of Figure 1 shows that the model's key assumption of proportionality is not violated, as the lines do not intersect.

\footnotetext{
${ }^{1}$ We define the average individual as being an 87 year old Age Pensioner, living alone in a NSW metropolitan area without socioeconomic advantage or disadvantage (SEIFA quintile 3), with Year 11 education, without private health insurance, and limited social resources (has someone to share concerns with). We do not specify their precise health status, but assign the mean self-reported health value.
} 
[Figure 1 about here]

The subdistributional hazard ratios reported in Table 3 indicate how the baseline hazard rate shifted according to different variables. A ratio greater than 1 reflects a faster rate of entry to services, or shorter wait times. Conversely, a ratio less than one reflects longer wait times. Results are shown separately for individuals approved for both community care and PRAC, and for those approved for either PRAC only or community care only. While death was included as a competing risk, results are not reported here.

[Table 3 about here] 
For those approved for both community-based care and PRAC, age was a significant socioeconomic factor for those entering PRAC. Controlling for assessed need (and the competing risk of death), older age (over 87 years) was associated with shorter elapsed times for PRAC. Living alone had a statistically significant effect on access to both community care and PRAC - those living alone entered PRAC more quickly, and accessed community care more slowly, than those living with partners or family. There was some evidence that, for individuals approved for either PRAC or community-care, low social resources were associated with longer wait times.

For individuals with approval for PRAC services only, other socioeconomic factors featured more prominently. Having high educational attainment increased the hazard function and was associated with lower wait times. Living in an outer regional area reduced the hazard rate and increased wait times, indicating that geographical accessibility to PRAC services may also be an issue. For individuals approved for PRAC services (either solely or in tandem with community-care services), having the ACAP assessment take place in hospital increased entry rates to PRAC, and lowered wait times. This is as expected, as hospital-based assessments reflect both poorer health and higher pressure to resolve the individual's circumstances than home-based assessments.

With regards to the needs-based variables, we did not report on these individually, as there were many, and most were found to be individually statistically insignificant - full results available upon request. The health conditions variables were highly collinear and found to be jointly significant across the three models. The variables denoting need for assistance with daily activities were also jointly significant. The low p-values reported in Table 3 indicated that assessed need is a primary driver of wait times for those approved for PRAC and community care services, and greater need was associated with shorter wait times.

\section{Discussion}

Our research found that assessed need was the primary driver of wait times for individuals with approval to access services, along with age and whether the individual lived alone. From an equity perspective, our results also suggest that there is a socioeconomic gradient of access to PRAC. For those waiting to access permanent residential care, more educated individuals were able to access care more quickly. This may reflect their greater capacity to navigate a complex system, but may 
also represent greater financial and social resources. Our results also showed that geographical remoteness affected accessibility, emphasising the urban-rural divide.

From a health system perspective, prolonged wait times risk increasing the burden on the health system, and entail downstream costs to both the aged and health care systems. Those with unmet need may see their health deteriorate, because they are physically unable to navigate access to healthcare, are already in poor health, or are exposed to risks such as falls and fractures. For those trying - and failing - to access community-based care, unmet need may drive individuals into the costlier PRAC option. It is difficult to draw firm conclusions because, until recently, data linking health and aged care outcomes, or service provider and consumer outcomes, were unavailable. One recent study looked at home care approvals granted between 2003 and 2013 for people in South Australia [15]. This study followed people after admission to community care and showed that longer wait times for home care entailed a higher risk of admission to residential care as well as a higher mortality rate.

Reducing wait times for home care is an important goal for aged care provision. Over the past five years, a large suite of aged care reforms has been rolled out in an attempt to improve access to aged care that better meets older people's needs. Our results suggest that reforms aimed at improving consumer information (e.g. introduction of the MyAgedCare website), and at improving geographical accessibility of services (e.g. changes to Multi-Purpose Services), may have been helpful in reducing wait times. However, more recent government data suggest that prolonged waiting times are still common and may be increasing. Better data on factors that drive demand for aged care are essential if aged care planning and service provision is to keep pace with demands of our ageing population.

Our study faced numerous limitations. First, our analysis pre-dates the major suite of policy reforms rolled out from mid-2013. However, to our knowledge, no previous study has examined on variations in waiting times empirically as a baseline for evaluating ongoing changes, and our analysis aims to provide such a baseline. In addition, we did not observe supply-side or service-provider level (e.g number of available beds), which would almost certainly affect wait times. We observed only data on older women, and not men. This omission may have biased our results if, for instance, men are more likely to delay or accelerate access to services in a way that is systematically different to women; however, access to aged care services, particularly PRAC does skew towards women due to their longer life expectancy. 


\section{References}

1. Knaus, C. Two-year wait for home aged care 'unacceptable', advocates say. The Guardian Australia, May 17, 2018. [Cited July 27, 2018] Available from URL: https:/www.theguardian.com/australianews/2018/may/17/two-year-wait-for-home-aged-care-unacceptable-advocates-say

2. Brown,B. Wait for home-care packages pushing elderly into nursing homes. Sydney Morning Herald, April 12, 2018. [Cited July 27, 2018] Available from URL:

https://www.smh.com.au/money/planning-and-budgeting/wait-home-care-packages-elderly-nursinghomes-20180411-p4z92u.html

3. Productivity Commission. Caring for Older Australians. Report No.53, Final inquiry report. Australian Government, Canberra, 2011, p.104.

4. Department of Health. Home Care Packages Program, Data Report 27 February - 30 June 2017. Australian Government, Canberra. [Cited July 15 2018] Available from URL: https://genagedcaredata.gov.au/Resources/Home-care-packages-program-data-report-2017

5. Department of Health. Home Care Packages Program, Data Report 1 January - 31 March 2018. Australian Government, Canberra. [Cited Feb. 5 2019] Available from URL: https://www.genagedcaredata.gov.au/www_aihwgen/media/Home_care_report/HCP-Data-Report2017\%E2\%80\%9318-3rd-Qtr.pdf.

6. Austrtalian Government. Expected wait times. Australian Government, Canberra, 2019. [Cited Feb. 5 2019] Available from URL: https://www.myagedcare.gov.au/help-home/home-carepackages/accessing-home-care-package.

7. Productivity Commission. Report on Government Services 2019, Volume F, Chapter 14. Australian Government, Canberra. Available from URL: https://www.pc.gov.au/research/ongoing/report-ongovernment-services/2017/community-services/aged-care-services/rogs-2017-volumef-chapter14.pdf.

8. Productivity Commission. Report on Government Services 2018, Volume F, Chapter 14. Australian Government, Canberra. Available from URL: https://www.pc.gov.au/research/ongoing/report-ongovernment-services/2018/community-services/aged-care-services

9. Brown WJ, Dobson AJ, Bryson L, Byles JE.. The Australian Longitudinal Study on Women's Health: on the progress of the main cohort studies. Journal of Women's Health \& Gender-Based Medicine, 1999; 8(5): 681-688.

10. Brilleman SL, Pachana NA, Dobson AJ. The impact of attrition on the representativeness of cohort studies of older people. BMC Medical Research Methodology. 2010;10:71.

11. Karmel R, Anderson P, Gibson D, Peut A, Duckett S, Wells Y. Empirical aspects of record linkage across multiple data sets using statistical linkage keys: the experience of the PIAC cohort study, BMC Health Services Research, 2010; 10:41.

12. Fine JP, Gray RJ. A proportional hazards model for the subdistribution of a competing risk. Journal of the American Statistical Association. 1999; 94:496-509.

13. Kendig H, Mealing N, Carr R, Lujic S, Byles J, Jorm L. Assessing patterns of home and community service use and client profiles in Australia: a cluster analysis approach using linked data. Health and Social Care in the Community. 2012; 20(4): 375-387.

14. Productivity Commission. Caring for Older Australians. Report No.53, Final inquiry report. Australian Government, Canberra, 2011.

15. Visvanathan, R., Amare, A.T., Wesselingh, S. et al. Prolonged wait time prior to entry to Home Care Packages increases the risk of mortality and transition to permanent residential aged care services: Findings from the registry of older South Australians (ROSA). Journal of nutrition, health and aging. 2018. https://doi.org/10.1007/s12603-018-1145-y. 


\begin{tabular}{|c|c|c|c|c|c|}
\hline Characteristic & $\begin{array}{l}\text { Did not } \\
\text { use } \\
\text { services }\end{array}$ & $\begin{array}{c}\text { Community } \\
\text { Care }\end{array}$ & $\begin{array}{l}\text { Permanent } \\
\text { residential } \\
\text { care }\end{array}$ & Died & Total \\
\hline Days since approval & 548 & 159 & 101 & 255 & 129 \\
\hline \multicolumn{6}{|l|}{ Socioeconomic profile } \\
\hline Age & 89.0 & 85.6 & 86.3 & 85.2 & 86.1 \\
\hline Lives alone & 55.3 & 58.4 & 63.6 & 60.9 & 61.5 \\
\hline Concession cardholder & 83.0 & 84.4 & 86.2 & 89.4 & 85.5 \\
\hline Has private health insurance & 50.0 & 61.1 & 60.8 & 66.7 & 60.9 \\
\hline \multicolumn{6}{|l|}{ Educational attainment } \\
\hline Year 11 and below & 70.5 & 71.2 & 71.3 & 84.8 & 71.4 \\
\hline Completed Year 12 & 13.6 & 11.9 & 12.7 & 8.7 & 12.4 \\
\hline VET qualification & 13.6 & 11.7 & 11.5 & 4.3 & 11.5 \\
\hline Bachelor degree and higher & 2.3 & 5.2 & 4.5 & 2.2 & 4.7 \\
\hline \multicolumn{6}{|l|}{ SEIFA quintile } \\
\hline $1=$ Most disadvantaged & 19.1 & 20.4 & 21.3 & 27.3 & 21.0 \\
\hline 2 & 21.3 & 19.3 & 21.0 & 22.7 & 20.3 \\
\hline 3 & 19.1 & 20.4 & 20.3 & 11.4 & 20.3 \\
\hline 4 & 19.1 & 21.2 & 19.3 & 13.6 & 20.0 \\
\hline $5=$ Least disadvantaged & 21.3 & 18.6 & 18.1 & 25.0 & 18.4 \\
\hline \multicolumn{6}{|l|}{ Geographical isolation } \\
\hline Metropolitan & 57.4 & 44.5 & 45.7 & 54.5 & 45.4 \\
\hline Inner regional & 27.7 & 38.6 & 38.0 & 25.0 & 38.0 \\
\hline Outer regional/ Remote & 14.9 & 17.0 & 16.2 & 20.5 & 16.5 \\
\hline \multicolumn{6}{|l|}{ State } \\
\hline NSW & 43.5 & 40.4 & 33.5 & 46.8 & 36.4 \\
\hline Victoria & 28.3 & 18.9 & 26.2 & 25.5 & 23.4 \\
\hline Queensland & 17.4 & 18.4 & 17.5 & 21.3 & 17.9 \\
\hline South Australia & 0.0 & 10.5 & 9.6 & 2.1 & 9.8 \\
\hline Western Australia & 10.9 & 7.6 & 7.8 & 4.3 & 7.7 \\
\hline Tasmania & 0.0 & 2.3 & 4.2 & 0.0 & 3.4 \\
\hline Northern Territory & 0.0 & 0.1 & 0.2 & 0.0 & 0.1 \\
\hline $\mathrm{ACT}$ & 0.0 & 1.9 & 1.0 & 0.0 & 1.3 \\
\hline \multicolumn{6}{|l|}{ Social resources } \\
\hline Lacks someone to help with daily activities & 40.0 & 35.7 & 36.2 & 35.7 & 36.0 \\
\hline Lacks someone to share worries with & 4.3 & 16.2 & 16.7 & 14.9 & 16.3 \\
\hline $\mathrm{n}$ & 47 & 1882 & 2948 & 47 & 4924 \\
\hline
\end{tabular}




\begin{tabular}{|c|c|c|c|c|c|}
\hline Characteristic & $\begin{array}{c}\text { Has not used } \\
\text { services }\end{array}$ & $\begin{array}{c}\text { Community } \\
\text { Care }\end{array}$ & $\begin{array}{l}\text { Permanent } \\
\text { residential } \\
\text { care }\end{array}$ & Died & Total \\
\hline Days since approval & 548 & 159 & 101 & 255 & 129 \\
\hline \multicolumn{6}{|l|}{ Needs } \\
\hline \multicolumn{6}{|l|}{ Self-assessed health } \\
\hline Very good/excellent & 21.7 & 14.7 & 17.3 & 21.3 & 16.4 \\
\hline Good/fair & 76.1 & 77.3 & 75.4 & 72.3 & 76.1 \\
\hline Poor & 2.2 & 7.9 & 7.4 & 6.4 & 7.5 \\
\hline Mental/behavioural (incl dementia) & 10.6 & 35.9 & 47.6 & 27.7 & 42.6 \\
\hline Pain, frequent falls, disorientation & 78.7 & 56.5 & 62.3 & 46.8 & 60.1 \\
\hline \multicolumn{6}{|l|}{ Needs assistance with... } \\
\hline Communication & 89.4 & 87.1 & 78.3 & 83.0 & 81.8 \\
\hline Health & 29.8 & 29.2 & 13.7 & 19.1 & 19.8 \\
\hline Home maintenance & 10.6 & 20.1 & 24.9 & 31.9 & 23.0 \\
\hline Meals & 19.1 & 18.9 & 13.2 & 17.0 & 15.5 \\
\hline Movement & 78.7 & 86.5 & 68.5 & 57.4 & 75.4 \\
\hline Self-care & 51.1 & 41.8 & 22.1 & 27.7 & 30.0 \\
\hline Social activities & 19.1 & 16.8 & 10.6 & 19.1 & 13.1 \\
\hline Transport & 21.3 & 7.6 & 4.9 & 6.4 & 6.1 \\
\hline $\mathrm{n}$ & 47 & 1882 & 2,948 & 47 & 4,924 \\
\hline
\end{tabular}


Table 3. Competing risks subdistribution hazard ratios, by approval status

\begin{tabular}{|c|c|c|c|c|c|c|c|c|c|c|c|c|}
\hline \multirow[t]{4}{*}{ Variable } & \multicolumn{6}{|c|}{ Approved for community care and PRAC } & \multirow{3}{*}{\multicolumn{3}{|c|}{$\begin{array}{l}\text { Approved for PRAC only } \\
\text { Lower }\end{array}$}} & \multirow{2}{*}{\multicolumn{3}{|c|}{$\begin{array}{l}\text { Approved for community } \\
\text { care only }\end{array}$}} \\
\hline & \multicolumn{3}{|c|}{ Entry to PRAC } & \multirow{2}{*}{\multicolumn{3}{|c|}{ Entry to community care }} & & & & & & \\
\hline & & Lower & Upper & & Lower & & & & & & Lower & Upper \\
\hline & $\begin{array}{l}\text { Hazard } \\
\text { ratio }\end{array}$ & $\begin{array}{c}95 \% \\
\text { CI }\end{array}$ & $\begin{array}{c}95 \% \\
\text { CI }\end{array}$ & $\begin{array}{l}\text { Hazard } \\
\text { ratio }\end{array}$ & $\begin{array}{c}95 \% \\
\text { CI }\end{array}$ & $\begin{array}{l}95 \% \\
\mathrm{CI}\end{array}$ & $\begin{array}{l}\text { Hazard } \\
\text { ratio }\end{array}$ & $\begin{array}{c}95 \% \\
\mathrm{CI}\end{array}$ & $\begin{array}{c}\text { Upper } 95 \% \\
\text { CI }\end{array}$ & $\begin{array}{l}\text { Hazard } \\
\text { ratio }\end{array}$ & $\begin{array}{c}95 \% \\
\text { CI }\end{array}$ & $\begin{array}{c}95 \% \\
\text { CI }\end{array}$ \\
\hline Age & $1.05 * *$ & 1.00 & 1.10 & 0.97 & 0.94 & 1.01 & 1.01 & 0.98 & 1.04 & 0.99 & 0.95 & 1.04 \\
\hline Lives alone & $1.42 * * *$ & 1.14 & 1.75 & $0.80 * *$ & 0.67 & 0.95 & 1.01 & 0.88 & 1.16 & 1.13 & 0.92 & 1.39 \\
\hline Concession cardholder & 1.21 & 0.87 & 1.70 & 0.84 & 0.66 & 1.08 & 0.98 & 0.79 & 1.23 & 1.33 & 0.97 & 1.82 \\
\hline Has private health insurance & 0.98 & 0.79 & 1.21 & 0.98 & 0.82 & 1.16 & 1.06 & 0.92 & 1.22 & 1.06 & 0.87 & 1.30 \\
\hline \multicolumn{13}{|l|}{ Educational attainment } \\
\hline Completed Year 12 & 1.22 & 0.91 & 1.63 & 0.92 & 0.71 & 1.19 & 1.11 & 0.91 & 1.35 & 1.06 & 0.75 & 1.51 \\
\hline VET qualification & 1.21 & 0.90 & 1.61 & 0.82 & 0.64 & 1.06 & 1.07 & 0.87 & 1.30 & 1.31 & 0.96 & 1.78 \\
\hline Bachelor degree and higher & 1.18 & 0.74 & 1.87 & 0.87 & 0.56 & 1.35 & $1.32 * *$ & 1.02 & 1.70 & 1.38 & 0.96 & 1.98 \\
\hline \multicolumn{13}{|l|}{ SEIFA quintile } \\
\hline 2 & 0.88 & 0.65 & 1.19 & 1.04 & 0.81 & 1.35 & 0.98 & 0.80 & 1.19 & 0.80 & 0.58 & 1.12 \\
\hline 3 & 0.80 & 0.59 & 1.08 & 1.09 & 0.86 & 1.39 & 1.19 & 0.97 & 1.47 & 0.87 & 0.65 & 1.18 \\
\hline 4 & 0.82 & 0.60 & 1.11 & 1.10 & 0.85 & 1.42 & 0.95 & 0.77 & 1.18 & 1.05 & 0.79 & 1.40 \\
\hline $5=$ Least disadvantaged & 1.01 & 0.72 & 1.43 & 0.89 & 0.67 & 1.18 & 0.91 & 0.71 & 1.17 & 0.85 & 0.61 & 1.19 \\
\hline \multicolumn{13}{|l|}{ Geographical isolation } \\
\hline Inner regional & 1.08 & 0.85 & 1.38 & 0.92 & 0.76 & 1.13 & 1.01 & 0.88 & 1.17 & 0.92 & 0.72 & 1.16 \\
\hline Outer regional/ Remote & 1.09 & 0.80 & 1.49 & 0.96 & 0.75 & 1.22 & $0.71 * * *$ & 0.58 & 0.87 & 0.74 & 0.54 & 1.01 \\
\hline \multicolumn{13}{|l|}{ Social resources } \\
\hline Lacks someone to help with daily & 0.98 & 0.78 & 1.23 & 0.99 & 0.82 & 1.19 & 1.10 & 0.96 & 1.27 & $0.73 * *$ & 0.57 & 0.94 \\
\hline Lacks someone to share worries & 1.06 & 0.80 & 1.39 & 0.98 & 0.78 & 1.24 & $0.80 * *$ & 0.67 & 0.96 & 1.12 & 0.85 & 1.48 \\
\hline Hospital-based ACAP & $1.62 * * *$ & 1.21 & 2.17 & 0.83 & 0.63 & 1.09 & $1.85^{* * *}$ & 1.61 & 2.14 & 0.90 & 0.63 & 1.28 \\
\hline \multicolumn{13}{|l|}{ Test of joint significance } \\
\hline Health conditions & \multicolumn{3}{|c|}{$<0.001$} & \multicolumn{3}{|c|}{0.3835} & \multicolumn{3}{|c|}{$<0.001$} & \multicolumn{3}{|c|}{0.0012} \\
\hline Daily assistance needed & \multicolumn{3}{|c|}{$<0.001$} & \multicolumn{3}{|c|}{$<0.001$} & \multicolumn{3}{|c|}{$<0.001$} & \multicolumn{3}{|c|}{0.1060} \\
\hline $\mathrm{n}$ & \multicolumn{6}{|c|}{1095} & \multicolumn{3}{|c|}{1,068} & \multicolumn{3}{|c|}{449} \\
\hline
\end{tabular}

Subdistribution hazard ratios are reported. Full results for geographical state of residence, need and health conditions are omitted for brevity, but are available on request. Age has been recoded as deviation from its mean value of 87 years. *** Significant at the 1 percent level. ** Significant at the 5 percent level. 
